\title{
Morphometry of subcutaneous fat lobules of the abdomen and its implication in obesity
}

\section{Arvind K. Pandey ${ }^{1}$, Pramod Kumar ${ }^{2,3}$, Kodavoor Shrinivas Aithal', Rama Kotian Sushma ${ }^{1}$, Antony Sylvan D'Souza ${ }^{1}$}

${ }^{1}$ Department of Anatomy, Kasturba Medical College, Manipal University, Manipal, Udupi 576104, Karnataka, India.

${ }^{2}$ Department of Plastic Surgery, King Abdulaziz Specialist Hospital, Sakaka 42421, Al-Jouf, Saudi Arabia.

${ }^{3}$ Department of Plastic Surgery and Burns, Kasturba Medical College, Manipal 576104, Karnataka, India.

${ }^{4}$ Department of Physics, MIT, Manipal University, Manipal, Udupi 576104, Karnataka, India.

Address for correspondence: Dr. Pramod Kumar, Department of Plastic Surgery, King Abdulaziz Specialist Hospital, Sakaka 42421, Al-Jouf, Saudi Arabia. E-mail: pkumar86@hotmail.com

\begin{abstract}
Aim: The subcutaneous fat in the lower abdomen (LA) is more resistant to resorption as compared to the upper abdomen (UA). Males and females have variability in fat deposition and resorption in the abdominal region. Hence, there could be a difference in morphology of fat cells of these regions. The present study aims to identify the differences in morphology of subcutaneous fat lobules of upper and LA. Methods: Subcutaneous fat samples were collected from upper and LA of 40 cadavers (33 males and 7 females). The shape, the arrangement, and the color of superficial and deep subcutaneous fat lobules were observed. The height and width were recorded for larger fat lobules. Results: There was a difference in the color, shape, size, and arrangement of the fat lobules between the two locations. Height $(P=0.042)$ and width $(P=0.008)$ of deep subcutaneous fat of LA were significantly larger than the UA in males while the height of superficial fat $(P=0.016)$ was significantly larger in LA than the UA in females. Height of the deep fat of UA $(P=0.018)$ and width of deep fat of the LA $(P=0.020)$ were significantly larger in females as compared to males. Conclusion: There was a significant difference in the morphology of the superficial and deep subcutaneous fat based on location and gender of the patient.
\end{abstract}

Key words:

Abdomen, morphometry, obesity, resorption, subcutaneous fat

\section{INTRODUCTION}

The development of liposuction and lipectomy in reconstructive surgery has enhanced interest in the study of superficial fascia and subcutaneous fat deposits of the abdomen. ${ }^{[1-3]}$ Furthermore, a strong relationship exists between obesity, insulin resistance, and cardiometabolic risk factors. ${ }^{[4-7]}$

\begin{tabular}{|l|l|}
\multicolumn{2}{|c|}{ Access this article online } \\
\hline Quick Response Code: & Website: \\
\hline & www.parjournal.net \\
\hline & \\
\hline
\end{tabular}

Subcutaneous tissue constitutes $85 \%$ of total adipose tissue mass and visceral fat constitutes the remaining $15 \% .{ }^{[8]}$ Subcutaneous fat in adults is called white fat and its quantitative distribution is variable in different sexes..$^{[9,10]}$

There are two distinct types of subcutaneous fat: superficial and deep. ${ }^{[8]}$ The superficial fat exists between the skin

This is an open access article distributed under the terms of the Creative Commons Attribution-NonCommercial-ShareAlike 3.0 License, which allows others to remix, tweak, and build upon the work non-commercially, as long as the author is credited and the new creations are licensed under the identical terms.

For reprints contact: reprints@medknow.com

How to cite this article: Pandey AK, Kumar P, Aithal KS, Sushma RK, D'Souza AS. Morphometry of subcutaneous fat lobules of the abdomen and its implication in obesity. Plast Aesthet Res 2015;2:286-9.

Received: 05-12-2014; Accepted: 12-01-2015 
and the superficial fascia whereas the deep fat occupies the area between the superficial fascia and the muscles. Superficial layer is richly vascularized and results in cellulite formation when it is hypertrophied. The deep layer of fat is called localized fat deposit (LFD) when it is hypertrophied. LFD is excessive bulge producing contour deformity of the region. ${ }^{[1]}$ The subcutaneous fat deposits in the lower abdomen (LA) do not get absorbed easily by dieting and exercise, compared to the upper abdomen (UA).

The present study was carried to find the difference in morphology of subcutaneous fat lobules, as an initial step to explore the different re-absorption pattern of deposited fat different location of abdomen and different gender.

\section{METHODS}

This study included 40 fresh (within 6-10 h after death) adult cadavers (33 males and 7 females) of age varied between 18 and 70 years collected from the Department of Forensic Medicine, Kasturba Medical College, Manipal. All cadavers ( $<10 \mathrm{~h}$ after death) of body mass index more than 19.5 were included in this study. None of the cases had lipodistrophies or any kind of hormonal imbalance that causes abnormal fat accumulation.

This study was approved by the Institutional Human Ethics Committee (IEC 111/2009).

\section{Data collection}

Samples of the subcutaneous fat lobules were collected from UA ( $3 \mathrm{~cm}$ above the umbilicus) and LA $(3 \mathrm{~cm}$ below the umbilicus) at the mid-clavicular line. The shape, arrangement, and color of the superficial and deep subcutaneous fat lobules were observed and recorded. The larger fat lobules (in width and height) in the region under study were identified, and their height and width were noted. The maximum distance between the upper and lower end of the fat lobule was considered as the height while the maximum distance between the anterior and posterior part of the lobule was considered as the width [Figure 1]. The readings of maximum height and width were taken at the accuracy of $10 \mu \mathrm{m}$ using metal casing Electronic Digital

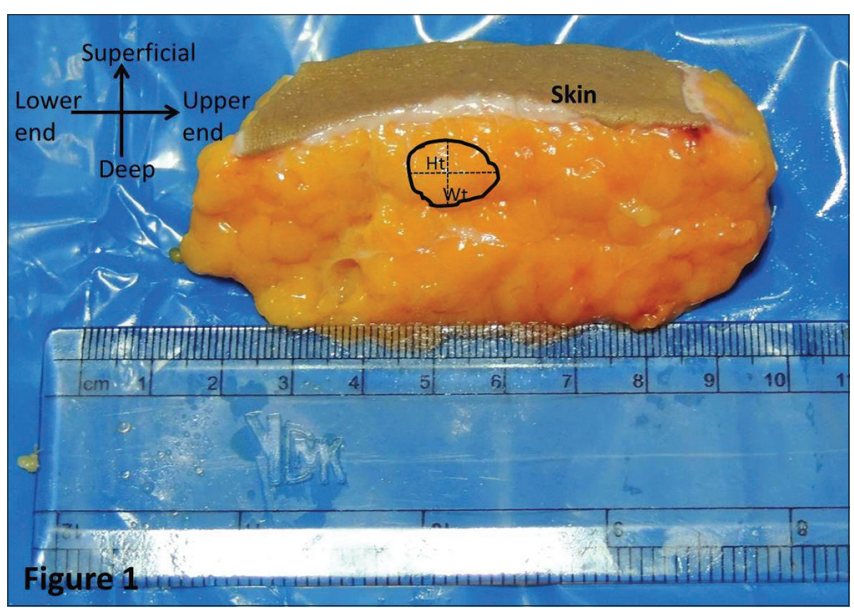

Figure 1: The schematic representation of the measurements of a fat lobule. Height $(\mathrm{Ht})$ : the maximum distance between the upper and lower end of the fat lobule; Width $(\mathrm{Wt})$ : the maximum distance between the anterior and posterior part of the lobule
Calipers (series-sc02, Guilin Gunglv measuring instrument Co. Ltd., Guilin, China); and the average readings of 3 larger lobules was calculated for further analysis.

Statistical analysis was performed using the SPSS 15 package (SPSS, IBM Company). Data were expressed as mean \pm standard deviation (SD) and 95\% confidence interval. Paired sample $t$-test was applied for comparing UA and LA parameters in each sex. Independent sample $t$-test was applied for comparing the parameters between males and females. In addition, Pearson's correlation test was applied to correlate the parameters of the upper and LA. $P<0.05$ was considered as statistically significant.

\section{RESULTS}

There was a difference in the color, shape, size, and arrangement of the fat lobules at different locations. Subcutaneous fat of the UA was dark yellowish in color whereas LA subcutaneous fat was yellowish in color, and deeper fat lobules were pale yellow [Figure 2].

The fat lobules from the superficial layer were elongated and arranged perpendicular to the skin. The fat lobules from deeper layers of UA were rounded in shape whereas the fat lobules from LA were elongated and arranged perpendicular to the skin. Most dependent (lowest in standing position) lobules were larger in size (both in height and width).

Height $(P=0.042)$ and width $(P=0.008)$ of deep fat of LA were significantly more than UA in males [Table 1] while the height of superficial fat $(P=0.016)$ was significantly more in LA than the UA in females [Table 2].

Independent sample $t$-test was applied to compare the means of width and height of fat lobules-in males and females. The height of deep fat of UA $(P=0.018)$ and width of deep fat of LA $(P=0.020)$ were significantly larger in females than males.

Pearson correlation between height $(r=0.403, P=0.010)$ and width $(r=0.585, P<0.01)$ of the superficial fat of

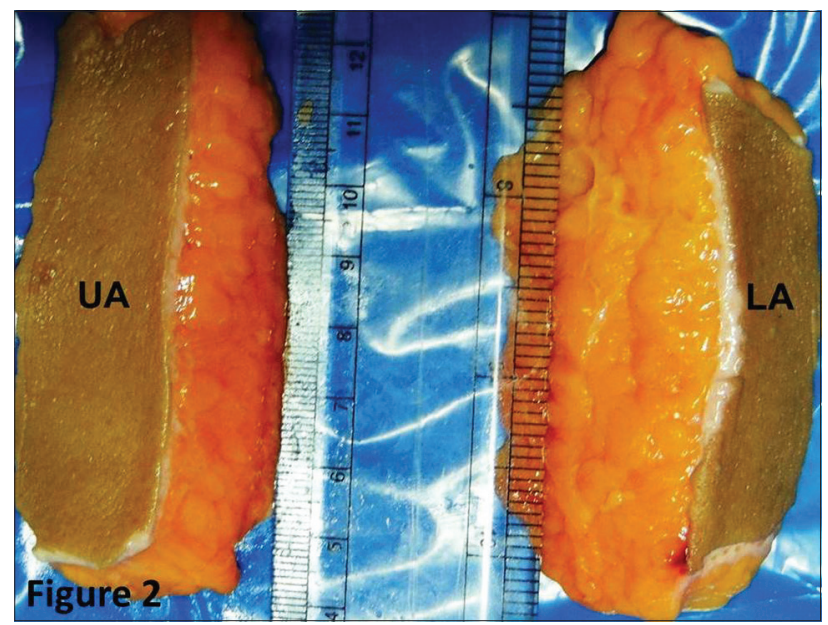

Figure 2: The subcutaneous fat of upper and lower abdomen. Subcutaneous fat of the UA was dark yellowish in color whereas in the LA, subcutaneous fat was yellowish in color. UA: Upper abdomen, LA: Lower abdomen 
Table 1: Morphometry of subcutaneous fat lobules in males

\begin{tabular}{|c|c|c|c|c|c|c|}
\hline \multirow[t]{3}{*}{ Parameters (cm) } & \multicolumn{2}{|c|}{ Mean \pm SD } & \multirow[t]{3}{*}{ Paired $t$} & \multirow[t]{3}{*}{$\boldsymbol{P}$} & \multirow{2}{*}{\multicolumn{2}{|c|}{$\begin{array}{l}95 \% \mathrm{Cl} \text { of } \\
\text { difference }\end{array}$}} \\
\hline & \multirow[t]{2}{*}{ Lower abdomen } & \multirow[t]{2}{*}{ Upper abdomen } & & & & \\
\hline & & & & & Lower & Upper \\
\hline Height of superficial subcutaneous fat & $0.706 \pm 0.213$ & $0.648 \pm 0.187$ & 1.394 & 0.173 & -0.026 & 0.141 \\
\hline Width of superficial subcutaneous fat & $0.570 \pm 0.168$ & $0.509 \pm 0.186$ & 1.991 & 0.055 & -0.001 & 0.122 \\
\hline Height of deep subcutaneous fat & $0.824 \pm 0.225$ & $0.730 \pm 0.227$ & 2.117 & 0.042 & 0.003 & 0.184 \\
\hline Width of deep subcutaneous fat & $0.782 \pm 0.222$ & $0.639 \pm 0.2449$ & 2.848 & 0.008 & 0.040 & 0.244 \\
\hline
\end{tabular}

SD: Standard deviation, Cl: Confidence interval

Table 2: Morphometry of subcutaneous fat lobules in females

\begin{tabular}{|c|c|c|c|c|c|c|}
\hline \multirow[t]{3}{*}{ Parameters (cm) } & \multicolumn{2}{|c|}{ Mean \pm SD } & \multirow[t]{3}{*}{ Paired $t$} & \multirow[t]{3}{*}{$P$} & \multirow{2}{*}{\multicolumn{2}{|c|}{$\begin{array}{l}95 \% \mathrm{Cl} \text { of } \\
\text { difference }\end{array}$}} \\
\hline & \multirow{2}{*}{ Lower abdomen } & \multirow{2}{*}{ Upper abdomen } & & & & \\
\hline & & & & & Lower & Upper \\
\hline Height of superficial subcutaneous fat & $0.743 \pm 0.229$ & $0.600 \pm 0.216$ & 3.333 & 0.016 & 0.038 & 0.247 \\
\hline Width of superficial subcutaneous fat & $0.657 \pm 0.171$ & $0.629 \pm 0.205$ & 0.603 & 0.569 & -0.087 & 0.144 \\
\hline Height of deep subcutaneous fat & $1.014 \pm 0.261$ & $0.971 \pm 0.269$ & 0.528 & 0.617 & -0.155 & 0.241 \\
\hline Width of deep subcutaneous fat & $1.00 \pm 0.173$ & $0.771 \pm 0.236$ & 2.359 & 0.056 & -0.008 & 0.465 \\
\hline
\end{tabular}

SD: Standard deviation, $\mathrm{Cl}$ : Confidence interval

the upper and LA revealed significant (2-tailed) positive correlation. The height $(r=0.491, P=0.001)$ of the deep fat of the upper and LA showed a positive correlation while the width $(r=0.301, P=0.059)$ of the deep fat of the upper and LA did not show positive correlation.

\section{DISCUSSION}

Superficial fat layer is richly vascularized, and when hypertrophied, it is responsible for cellulite. Embryologically it arises from the hypodermis of the integument. Hypertrophy of the deep layer of fat is unsightly and called LFD. LFDs are often difficult to lose-by exercise and diet. ${ }^{[11]}$

The superficial layer comprises of tightly packed adipocytes supported by dense fibrous network whereas the deep layer constitutes of loosely arranged adipocytes. Varied blood supply of the two layers was also reported. ${ }^{[12,13]}$ The superficial epigastric arteries (a branch of the femoral artery) supply to the superficial layers, veins drain into the femoral veins via the saphenous hiatus. Inferior epigastric and deep circumflex iliac arteries (branches of the external iliac artery) and the superior epigastric artery (a branch of the internal thoracic artery) supplies to the deep layer. ${ }^{[14]}$

In the present study, the color, shape, size and arrangement of fat lobules were different at different regions of the abdomen and these were in agreement with those reported by Yves. ${ }^{[11]}$ Although authors have mentioned the variability in the measurement (height or width) of the fat lobules, an extensive attempt was not made to study the differences in the superficial and deep fat of the upper and LA.

Current study revealed that the height $(0.824 \pm 0.225$ vs. $0.730 \pm 0.227, P=0.042)$ and width $(0.782 \pm 0.222$ vs.
$0.639 \pm 0.2449, P=0.008$ ) of the deep subcutaneous fat of the LA was significantly more than that in the UA in males. Whereas in females, the height of the superficial fat $(0.743 \pm 0.229$ vs. $0.600 \pm 0.216, P=0.016)$ was significantly larger in the LA than in the UA [Tables 1 and 2].

The height of deep fat of UA $(0.971 \pm 0.269$ vs. $0.730 \pm 0.227, P=0.018$ ) and width of deep fat of LA $(1.00 \pm 0.173$ vs. $0.782 \pm 0.222, P=0.020)$ were significantly more in females than males. This may be the reason for an increase in lower abdominal girth with weight gain in females. Our findings thus support observations concluded by Champe and Harvey. ${ }^{[15]} \mathrm{He} \mathrm{Q}$ et al. ${ }^{[16]}$ suggested that superficial and deep subcutaneous compartments may differ in the rate of fat deposition, lipolysis or both.

Even though in vivo signals and the pathways regulating lipid metabolism are more complex than those in a controlled in vitro study, the metabolic difference in the superficial and deep compartments may lead to varied rates of gain and loss. This may be due to changes in energy intake or other factors.

Accumulation of subcutaneous fat depicts the normal physiological buffer for high caloric diet with limited physical activity. This acts as a metabolic sink to store excess free fatty acids and glycerol as triglycerides in adipocytes..$^{[17]}$

Illouz $^{[1]}$ defined the resistant nature (to absorption) of the abdominal LFD and showed that the anatomy of fat lobules and its arrangement differ in different areas of the abdomen. The LFD in the central region of the abdomen is less resistant to resorption of fat and is strongly correlated with cardiovascular diseases. ${ }^{[5]}$ The present study on the morphometry of the superficial and deep subcutaneous fat in the upper and lower regions of the abdomen and in males and females reveals a significant 
difference in morphology of fat cells between the two regions and genders. Further studies are required to correlate anatomical variations with varied behavior of fat in different locations of body and gender types.

\section{Financial support and sponsorship}

Nil.

\section{Conflicts of interest}

There are no conflicts of interest.

\section{REFERENCES}

I. Illouz YG. History and current concepts of lipoplasty. Clin Plast Surg 1996;23:72|-30.

2. Fodor PB. Reflections on lipoplasty: history and personal experience. Aesthet Surg J 2009;29:226-31.

3. Matarasso A. Traditional abdominoplasty. Clin Plast Surg 2010;37:415-37.

4. Despre's JP. Abdominal obesity: the most prevalent cause of the metabolic syndrome and related cardiometabolic risk. Eur Heart J Suppl 2006;8:B4-12.

5. Yusuf S, Hawken S, Ounpuu S, Dans T, Avezum A, Lanas F, McQueen M, Budaj A, Pais P, Varigos J, Lisheng L. Effect of potentially modifiable risk factors associated with myocardial infarction in 52 countries (the INTERHEART study): case-control study. Lancet 2004;364:937-52.

6. Gorter PM, Olijhoek JK, van der Graaf Y, Algra A, Rabelink TJ, Visseren FL, SMART Study Group. Prevalence of the metabolic syndrome in patients with coronary heart disease, cerebrovascular disease, peripheral arterial disease or abdominal aortic aneurysm. Atherosclerosis 2004;173:363-9.

7. Sönmez K, Akçakoyun M, Akçay A, Demir D, Duran NE, Gençbay M, Degertekin M, Turan F. Which method should be used to determine the obesity, in patients with coronary artery disease? (body mass index, waist circumference or waist-hip ratio). Int J Obes Relat Metab Disord 2003;27:34I-6

8. Klein S, Fontana L, Young VL, Coggan AR, Kilo C, Patterson BW, Mohammed BS. Absence of an effect of liposuction on insulin action and risk factors for coronary heart disease. N Engl J Med 2004;350:2549-57.

9. Vague J. Sexual differentiation. A determinant factor of the forms of obesity 1947. Obes Res 1996:4:201-3.

10. Bahman T. Suction lipectomy and body sculpturing. Maryland heights. St. Louis: Mosby Year Company; 1986. p. 19-20.

II. Yves I. Body Sculpturing by Lipoplasty. Edinburgh: Churchill Livingstone; 1989. p. 29-32, 51.

12. Lee $Y$, Hong J], Bang C. Dual-plane lipoplasty for the superficial and deep layers. Plast Reconstr Surg 1999; 104:1877-84.

13. El-Mrakby HH, Milner RH. Bimodal distribution of the blood supply to lower abdominal fat: histological study of the microcirculation of the lower abdominal wall. Ann Plast Surg 2003;50:165-70.

14. Ahluwalia HS, Burger JP, Quinn TH. Anatomy of the anterior abdominal wall. Oper Tech Gen Surg 2004;6:147-55.

15. Harvey RA, Ferrier DR. Lippincott's Illustrated Reviews: Biochemistry. 5th ed. Philadelphia: Lippincott William and Wilkins; 20I I. p. 350.

16. He Q, Engelson ES, Kotler DP. A comparison of abdominal subcutaneous adipose tissue pattern in obese and lean HIV-infected women. J Nutr 2005; 135:53-7.

17. Freedland ES. Role of a critical visceral adipose tissue threshold (CVATT) in metabolic syndrome: implications for controlling dietary carbohydrates: a review. Nutr Metab (Lond) 2004;1:12. 